\title{
Studying the Effectiveness of a Proposed Methodology for Teaching Programming Labs Online and Students' Perspectives toward it during COVID-19: A Case Study of Hashemite University
}

\author{
https://doi.org/10.3991/ijim.v16i05.27123
}

Ayat Al Ahmad ${ }^{1(凶)}$, Randa Obeidallah ${ }^{2}$

${ }^{1}$ Faculty of Prince Al-Hussein Bin Abdallah II for IT, Department of Computer Science and Application, The Hashemite University, P. O Box 330127, Zarqa 13133, Jordan

${ }^{2}$ Faculty of Prince Al-Hussein Bin Abdallah II for IT, Department of Computer Information Systems, The Hashemite University, P. O Box 330127, Zarqa 13133, Jordan

ayat@hu.edu.jo

\begin{abstract}
E-learning had been fully implemented during the COVID-19 lockdown. This emerging teaching and learning method has overcome many challenges and demonstrated a great deal of potential. During the COVID-19 pandemic, programming labs courses at the Faculty of Information Technology at Hashemite University were amended to be fully online courses using different platforms. In this paper, an analysis study is performed to analyze students' perspectives and experiences toward the new learning approach during COVID-19. The new online learning methodology was exploited, applied, and evaluated for all programming labs. Data for this study were collected through a web structured survey to measure students' satisfaction with the new learning approach. The survey questions were categorized into five factors and validated by the Pearson correlation coefficient test. The results showed that $47.3 \%$ of students agreed that the new approach had created a virtual course environment similar to face-toface courses on campus. $46 \%$ of students requested upgrading and enhancing the adopted online evaluation system to obtain fairer assessment results. Students' records were also obtained and analyzed using the independent t-test, and comparing curves revealed that the mean of students' marks during COVID-19 has statistical significance. Examining curves of direct assessments brings to light the difference in the behavior of curves during COVID-19.
\end{abstract}

Keywords - ICT, VLEs, distance learning, programming labs, Microsoft Teams, LMS, YouTube, Facebook, eLearning, online learning, computer programming, education, independent t-test

\section{Introduction}

The lockdown during the COVID-19 pandemic forced many countries to apply remote learning in their schools and universities as a preventive measure against the spread of COVID-19. School and university closures affected more than one billion and 575 million students in 188 countries in 2020 [1]. 
COVID-19 prompted a swift evolution in digital education and ICT infrastructures, a process typically taking years to complete [6]. The availability and accessibility of the internet and computers are essential in remote/distance and blended learning. Before the pandemic, many universities had integrated Information and Communication Technology (ICT) to improve the traditional learning process [2]. Asynchronous learning management systems (LMSs) tools, which are web-based programs used to manage and organize educational material for students at any time and from any location, were adopted by universities. Such examples of LMSs include Moodle and Blackboard. LMSs are also considered an applicable method to administer online exams [3] [4].

The blended learning approach demonstrated a promising potential for moving forward with e-learning. Obeidallah et al. [5] investigated students' perceptions of a blended learning approach using Elluminate and Moodle at Hashemite University. The results indicated a positive attitude toward blended learning. The COVID-19 closure imposed the full use of e-learning by using synchronous Virtual Learning Environments (VLEs) tools to improve the communication process between students and instructors. VLEs allow instructors to be in a virtual classroom to communicate and interact with students in real-time. The new situation of remote learning is dependent on the internet, computers, and the ability to adapt to different types of technology. The COVID-19 crisis can be viewed as an opportunity to be more creative, innovative, and inspired when it comes to teaching and learning [12]. At the beginning of the lockdown in March 2020, faculty members at Hashemite University (HU) adopted the use of an asynchronous tool called ZOOM to continue the semester, in addition to the use of digital materials that were previously designed and uploaded in Moodle to complete the lessons and interact with students. Faculty members also used Facebook groups, Facebook Messenger, WhatsApp groups, and previously prepared videos uploaded to YouTube channels. In the summer semester of 2019/2020 and beyond, the administration of Hashemite University announced that all faculty members would use Microsoft Teams as the primary and formal Synchronous VLE to communicate with students, give virtual classes in real-time, and provide interactive lectures. A study conducted by Obeidat et al. [15] at Hashemite University showed a generally positive evaluation of 399 students' experiences of using different platforms of learning during COVID-19. Online exams and assessments were given to students using one of the official methods adapted by HU, such as Moodle, Microsoft Teams, or the official HU Exam online system. Microsoft Forms is used to design online exams and report the results through Microsoft Teams. Nevertheless, it is essential to demonstrate that some practical courses, such as laboratories, sports, and art, pose challenges to teach and learn using complete eLearning platforms due to the course nature and assessment process.

This paper demonstrates the importance of using laboratories (practical learning) within university education. The environment of teaching programming labs at Hashemite University before the COVID-19 pandemic will be presented and the new methodology of teaching programming labs during COVID-19 will be introduced. The suggested approach has been exploited, applied, and evaluated for all programming labs taught within the Faculty of Information Technology. Students study six programming labs in the Information Technology faculty (Introduction to $\mathrm{C}++$, Object-Oriented 1 (JAVA), Object-Oriented 2 (JAVA), Visual Basic, Web Programming, and Introduction to Databases). 
The objectives of this paper are:

1. Discuss the challenges of learning during the COVID-19 pandemic in general, and specifically for the programming labs students, and explore the most used hardware/ software tools by students during COVID-19.

2. Investigate undergraduate students' experiences and perceptions toward learning programming languages labs at Hashemite University during the COVID-19 lockdown.

3. Compare students' academic performance before and during COVID-19 using various analytical methods.

This paper is structured as follows: Section 2 presents a literature review, section 3 reviews the adopted methodology for teaching programming labs prior to COVID-19, and section 4 presents the teaching methodology for programming labs during the COVID-19 pandemic. The research methodology is explained in detail in section 5, and section 6 elucidates the results and discussions. Section 7 introduces the limitation of remote learning, and finally, conclusions and future works are illustrated in section 8 .

\section{Literature review}

Computer labs play a significant role in filling the gap between theoretical and practical (hands-on) learning. The main goal of laboratory coursework is to establish a connection between theoretical learning and practical application of the same knowledge. Currently, the computer programming lab course is taught using a Traditional Deductive Teaching Method (DTM), presenting theoretical concepts followed by examples and practical activities [21]. Many researchers examined, discussed, and analyzed practical learning aspects within labs and suggested new methodologies to enhance hands-on education. An approach based on phenomenography and variation theory was proposed by Thuné and Eckerdal [23], which highlighted the interaction between learning by theory and learning by practice during laboratory sessions. Data were collected via video by filming students working in pairs on computer programming assignments in a computer laboratory. Several issues related to programming labs are considered, such as preparing curriculums to be synchronized with theory classes, validating techniques to assess assignments and exams, especially for classes with a large number of students, using social media in teaching labs, and teaching programming labs remotely. Mishra et al. [13] highlighted the implementation process of online teaching-learning modes at Mizoram University in India and showed the importance of developing a curriculum reflecting rapid knowledge and learning experience changes. Course curriculum redevelopment and modern learning strategies and approaches are required to implement remote learning successfully [7] [8]. The analysis study by BayisaNateaSima and Perumal [22] highlighted problems students encountered in learning programming (knowledge, comprehension, application, analysis, synthesis, and evaluation). The study helped information technology students to develop their programming skills at Ambo University, Ethiopia. Khan et al. [21] redesigned teaching computer programming courses using Inductive Teaching Methods (ITM) that bank 
up general principles from specific examples, which leads to constructing and reconstructing knowledge using the student's experience. Aris [25] investigated through a case study to improve students' performance in introductory programming subjects. The study suggested many actions such as rearranging the syllabus, closely monitoring attendance, and providing individual attention for each student during lab sessions. Muthuprasad et al.'s study [14] helped to understand students' perceptions towards online learning depending on various attributes such as flexibility and convenience of online classes, broadband connectivity, and staff technical skills. Rai [20] introduced a one-on-one grading feedback methodology that was implemented in introductory computer science programming labs and played a significant role in encouraging freshmen students to code. The methodology encouraged students to perform hands-on coding and implement problems on the computers within labs. Furthermore, the lab assistants supported the instructors to conduct the lab successfully, and the instructor used a rubric to correct the code [20]. Virtual laboratories in programming teaching were highlighted by Alves et al. [24]. The new teaching approach used Virtual Programming Labs (VPL), which is open-source software that allows the management of programming assignments in Moodle. The process supported a faster assessment of projects and, thus, addressed the difficulties students face while performing programming activities. Learning programming languages is still a challenge for many students. Papadakis and Kalogiannakis [26] had taken advantage of the gamified approach and applied an educational experience by operating an accessible web platform (Classcraft) in the classroom. The result of the study showed that students' attitudes were positively affected by programming.

\section{$3 \quad$ Methodology for teaching programming labs prior to COVID-19}

Six programming labs are available within Prince Al-Hussein bin Abdullah II of the Information Technology faculty at Hashemite University. The labs have been settled within the curriculums of four programs established in the faculty of information technology at Hashemite University. The programs include the Department of Computer Science and Applications (CSA), the Department of Computer Information Systems (CIS), the Department of Software Engineering (SWE), and the Department of Business Information Technology (BIT). From an infrastructure perspective, the building that houses the IT faculty contains nine labs. The labs are equipped with modern computers, licensed software, a fast internet connection, a data show with a whiteboard, and air conditioners. A lab supervisor is assigned to each lab and is responsible for helping students solve technical issues and installing software. All the facilities create an ideal, encouraging environment for the student software innovations. The adopted approach before the COVID-19 pandemic was a blended approach of traditional learning, LMS (Moodle), and social networks (Facebook and YouTube). The face-to-face learning programming languages approach depended on live training with an instructor to solve practical problems. Instructors used the Moodle platform to organize courses and apply social media methodology during the educational process [27]. Figure 1 depicts the adopted approach for teaching lab before the COVID-19 pandemic. 


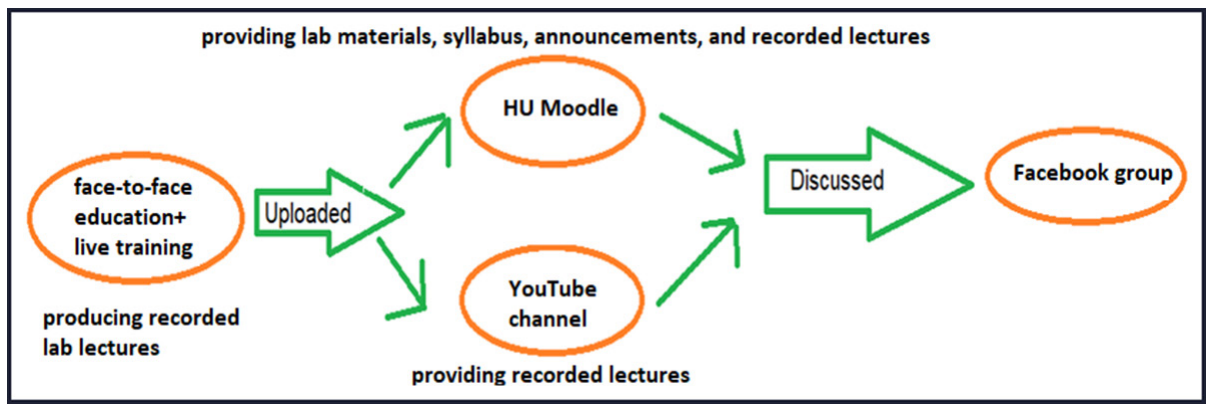

Fig. 1. Adopted approach for teaching lab before COVID-19 pandemic

The methodology of teaching programming labs before COVID-19 intelligibly improved the academic performance of lab students [27]. In the next section, the teaching methodology of the programming lab during COVID-19 will be discussed.

\section{Teaching methodology for programming labs during the COVID-19 pandemic}

At the beginning of the lockdown in March 2020, and during that critical period, the Hashemite University purveyed licensed copies of MS TEAM to all faculty members and all students, and at the same time, the faculty members were free to choose another tool that suited them, such as Zoom. To adjust to the transition to complete online learning, the administration decided that each faculty member must provide their faculty with weekly statistical information through filling out forms regarding the tools used to interact with students (MS TEAM, ZOOM, YouTube, Moodle, Facebook, Google Classroom, WhatsApp, etc.), the number of students that interacted, and the percentage of interacted students compared with the total number of students within the class. This statistical information contributed to forming general ideas about the components used within the proposed teaching methodology. The second semester of the academic year 2019/2020 and the summer semester of 2019/2020 are considered trial semesters for the sudden radical shift to complete online learning for faculty members and students. During those semesters, the online learning experience started to take shape. The HU E-learning center exerted great effort to provide students and faculty members with usernames and passwords to login into Microsoft Teams. Numerous training courses for faculty members were held to qualify faculty members to use the features embedded within the Microsoft Teams tool. Furthermore, many tutorials have been generated to enable students to learn by using the features of Microsoft Teams. The adopted approach for teaching IT labs has been applied since the first semester of 2020/2021. The methodology has been constructed based on seven axes: Firstly, provide weekly live virtual lab classes at the same time that is officially announced by the university administration in the formal class schedule. Secondly, upload copies of lab software to be made available for the students. Thirdly, in parallel with uploading copies of lab software, the lab instructor must provide students with online editors and software 
simulators to enable students who do not have a PC to apply the exercises using a mobile; the MS TEAM tool can be downloaded onto mobile devices. Fourthly, live lectures must be recorded and uploaded directly onto the Microsoft team channel. Fifthly, each student should be given time to analyze and solve the problems, as in face-to-face lectures on campus. Sixthly, Moodle and social media platforms must be utilized as extra resources to compensate for any shortage in achieving the goals of the lab, and finally, students must share their solutions, their syntax, and their logic errors with their colleagues. Figure 2 illustrates the methodology applied for teaching IT lab during the COVID-19 pandemic.

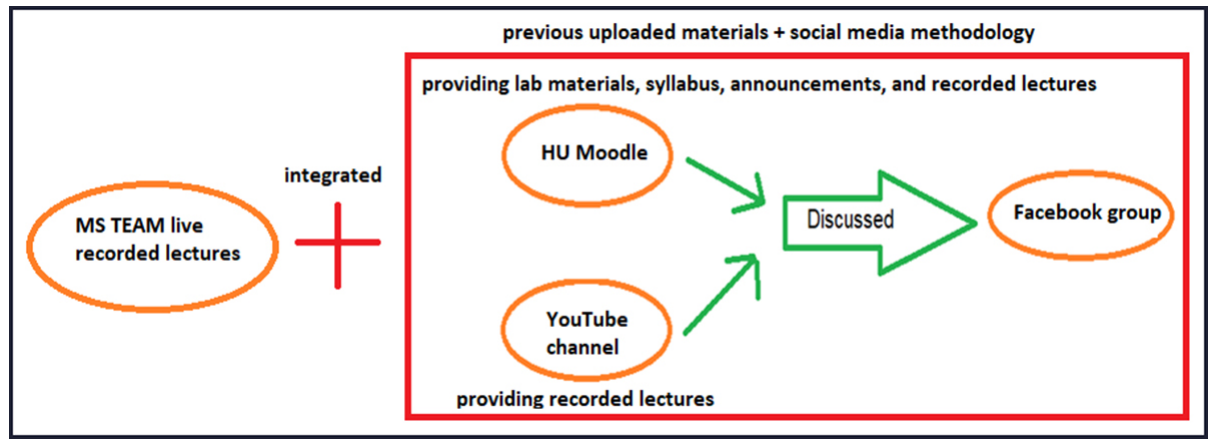

Fig. 2. The methodology applied for teaching IT lab during the COVID-19 pandemic

During the class period, the Microsoft team environment plays the role of a virtual classroom and a means to have an interactive lecture. Throughout the lecture, the instructor can provide certain students with the privilege of being able to share their program syntax with all members of the class team. However, some students face technical problems during their attempt to share their screens for several reasons, such as slow internet connections, attending class via smartphones, and other technical issues. In this case, the instructor asks the student to provide a screenshot of his/her solution or error bug and upload it to the meeting chat for evaluation and feedback. This suggested online approach had been applied for three semesters (first semester 2020/2021 second semester 2020/2021—summer semester 2020/2021) before resuming face-toface learning in October of 2021. In the next section, the study will question students' perspectives toward the online programming lab and analyze students' academic performance during COVID-19.perspectives toward the online programming lab and analyze students' academic performance during COVID-19.

\section{$5 \quad$ Research methodology}

\subsection{Data collection and validity test}

Data were collected using a structured web-based survey. The survey was conducted using Microsoft Forms and distributed through a link to students who attended one of the six programming labs during the academic year 2020/2021. Microsoft Forms 
automatically excludes all incomplete answers and provides an excel copy of the survey that can be imported easily into the SPSS statistical editor to be analyzed. A total of 222 students submitted their answers to the given questionnaire. Every student who participated in this survey had learned at least one programming lab face-to-face at the university campus. The questionnaire consisted of 11 items and included a 5-point Likert scale in addition to descriptive questions. The questions that utilized the 5-point Likert scale included the following points: Totally Agree (TA), Agree (A), Neutral (N), Disagree (DA), and Totally Disagree (TDA).

The 11 items were distributed to five factors that compose the survey:

- The first factor of the questionnaire (number of labs) aims to compare the number of programming labs statistically studied face-to-face with the many programming labs studied online during COVID-19 for each student within the sample; the first factor includes Q1 and Q2.

- The second factor of the survey (participation and attendance) aims to statistically investigate how the students participated and shared their solutions within live lectures and the most supported platforms by our proposed teaching methodology that they continuously adopted to study online programming labs. It is worth noting that the proposed methodology supported the MS-TEAM platform, the Moodle platform, and the YouTube platform. The second factor includes Q5 and Q6.

- The third factor of the survey (online evaluation system) aims to statistically study the evaluation system of programming labs during COVID-19. The third factor is designed and embedded within the survey to achieve the study's second objective, as mentioned previously in the introduction. The third factor includes Q7 and Q8.

- The fourth factor of the survey (the main challenge faced and the main used tools) aims to statistically study the main challenge that students encountered during COVID-19 and the leading hardware/software tools used to study programming laboratories. The fourth factor is designed to achieve the study's first objective, as mentioned previously in the introduction. The fourth factor includes Q3, Q4, and Q9.

- The fifth and last factor of the survey (students' perception toward online learning) aims to statistically study the general perspective of students toward the experience of studying programming labs online. The fifth factor is designed and embedded within the survey to achieve the study's second objective, as mentioned previously in the introduction. The fifth factor includes Q10 and Q11. The Pearson Correlation Coefficient test was used to check the validity of the survey and study the relationship between the factors of study and their items. Coefficient intervals are interpreted at the correlation levels as follows: $0.8-1.00$ indicates a very strong positive (negative) correlation, 0.6-0.799 shows a strong positive (negative) correlation, 0.4-0.599 suggests a moderate positive (negative) correlation, 0.2-0.399 denotes a low positive (negative) correlation, and 0.00-0.199 demonstrates a negligible correlation. As depicted in Table 1, each factor is examined via a correlation matrix, and all results computed for factors are reliable. 
Table 1. Pearson coefficients correlation for factor 1, factor 2, factor 3, factor 4, and factor 5

\begin{tabular}{|c|c|c|c|c|}
\hline \multicolumn{5}{|c|}{ Pearson Correlations } \\
\hline & Q1 & \multicolumn{2}{|c|}{ Q2 } & Level \\
\hline Factor 1 & $0.652 * *$ & \multicolumn{2}{|c|}{$0.629 * *$} & Strong Correlation \\
\hline \multicolumn{5}{|c|}{ Correlation is significant at the 0.01 level (2-tailed) } \\
\hline & Q5 & \multicolumn{2}{|c|}{ Q6 } & \multirow{2}{*}{ Very strong Correlation } \\
\hline Factor 2 & $0.828 * *$ & & & \\
\hline \multicolumn{5}{|c|}{ Correlation is significant at the 0.01 level (2-tailed) } \\
\hline & Q7 & \multicolumn{2}{|c|}{ Q8 } & \multirow{2}{*}{ Very strong Correlation } \\
\hline Factor 3 & $0.913^{* *}$ & & & \\
\hline \multicolumn{5}{|c|}{ Correlation is significant at the 0.01 level (2-tailed) } \\
\hline & Q3 & Q4 & Q9 & \multirow{2}{*}{$\begin{array}{l}\text { Moderate correlation and } \\
\text { very strong correlation }\end{array}$} \\
\hline Factor 4 & $0.548^{* *}$ & $0.492 * *$ & $0.872 * *$ & \\
\hline \multicolumn{5}{|c|}{ Correlation significance at level 0.01 ( 2 tailed) } \\
\hline & Q10 & \multicolumn{2}{|c|}{ Q11 } & \multirow{2}{*}{ Very Strong Correlation } \\
\hline Factor 5 & $0.939 * *$ & \multicolumn{2}{|c|}{$0.933 * *$} & \\
\hline Correlati & at the 0.0 & 2-tailed) & & \\
\hline
\end{tabular}

\section{$6 \quad$ Results and discussions}

The data from this study were analyzed, and the results are introduced in three subsections.

\subsection{Discussion of structured web-based survey responses}

As seen in Table 2, the survey results revealed many points. The majority of the students, $77.48 \%$, experienced learning one or two programming lab(s) face-to-face at the university, and $70.27 \%$ experienced learning one or two programming lab(s) online using Microsoft Teams in addition to different programming simulators.

The results of Q3 showed that $56.7 \%$ of students who responded to the survey used their laptops for coding during online lab lectures. This indicates that a substantial percentage of students did not have a laptop or PC and depended directly on mobile devices to attend online lectures and solve the required lab sheets. This is expected because Jordan is a developing country, and the pandemic directly affected the economic situation of many Jordanian families.

On the other hand, the availability of many learning applications for mobile phones and the revolution in interactive mobile digital touch screens have helped make mobiles an innovative learning tool. Moreover, mobile use is widespread, especially among young people and children. Mobile industries and mobile applications participate in reshaping the methods of education [28] [30]. 
To solve the lab sheets, students usually install programming software on their laptops or use PCs at the university during the class. Students can get the required software during face-to-face learning and efficiently solve installation issues by directly communicating with lab supervisors. $65.77 \%$ of students used installed software versus $24.77 \%$ who used online editors (Q4).

In Q6, the results showed that $50.9 \%$ of the students had attended live lectures to regularly follow up with the lab programming course, versus $29.73 \%$ who adopted studying the recorded live lectures, which the teacher uploaded in the MS TEAM environment. An essential consideration of not attending live meetings is that, according to $42.79 \%$ of students (Q9), the loss of competitive spirit and boredom during the live lab lecture was the main setback encountered.

The participation of students was highlighted in Q5 and showed that only 38.29\% of students had shared screenshots of their solutions in the live meeting chat versus the $33.78 \%$ who had shared their solutions using the share button embedded within MS TEAM. The main reason for the previous results is the considerable amount of pressure on the internet since all universities and schools transformed to online learning. Many students have complained about the inability to use the MS TEAM sharing button due to a weak internet connection. However, weak internet connectivity is only one of the major problems that students encountered.

The evaluation of students is a critical foundation of the educational system. Online exams, online quizzes, attending online lab lectures, and practicing through online lectures are the assessment tools that were employed in evaluating students during the COVID-19 online programming lab lectures. $22.5 \%$ of students totally disagree that holding online lab exams is a reliable and fair methodology for evaluation, $18.5 \%$ of students agree that holding online lab exams is a reliable and fair methodology for evaluation, and $30.6 \%$ of students are neutral, which leads to the next point. Most students were disquieted about the reliability and fairness of online lab exams, and, at the same time, most of the students showed dissatisfaction with their final lab grades during COVID-19 programming learning compared with those they obtained during face-toface programming lab learning at the university $(\mathrm{Q} 7, \mathrm{Q} 8)$. It is worth noting that the lab instructors made double effort to control cheating during online examinations.

Q10 and Q11 explored students' opinions toward learning programming lab in a completely remote setting. Just $17.6 \%$ of students totally agreed that they could code exercises inside the lab's manuals as if they were at the university. Only $28.8 \%$ of students agreed that they could code exercises inside the lab's manuals as if they were at the university, and $20.7 \%$ of students were neutral (Q11). A mere $21.2 \%$ of students totally agree that the experience of online programming lab courses was successful, $26.1 \%$ of students agree that the experience of online programming lab courses was successful, and $25.2 \%$ of students were neutral (Q10). $47.3 \%$ of students perceived the proposed methodology of teaching programming labs as positive (Q10). This percentage is considered reasonable and somewhat satisfactory, but, at the same time, it requires improvement through developing new teaching techniques dedicated to online learning [31]. 


\begin{tabular}{|c|c|c|c|c|c|c|}
\hline & 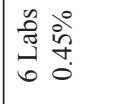 & 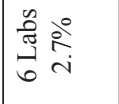 & \multirow{3}{*}{ 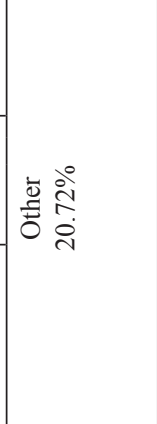 } & 這 $\frac{\partial}{\tilde{z}}$ & 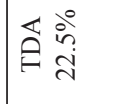 & 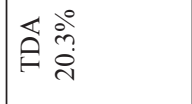 \\
\hline & 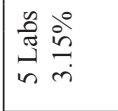 & 㓂 & & \multirow{2}{*}{ 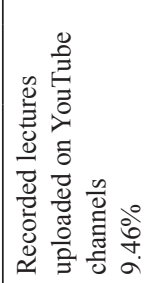 } & \multirow{2}{*}{ 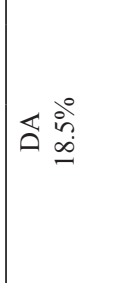 } & \multirow{2}{*}{ 苍究 } \\
\hline & 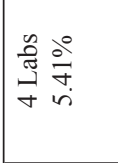 & 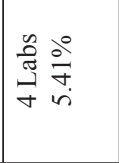 & & & & \\
\hline \multirow{3}{*}{ 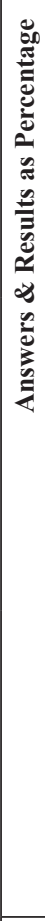 } & 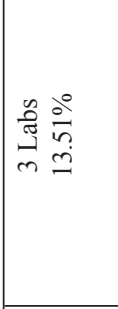 & 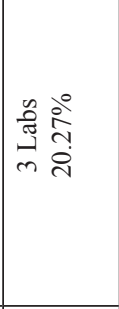 & 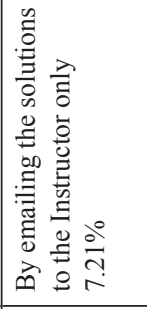 & 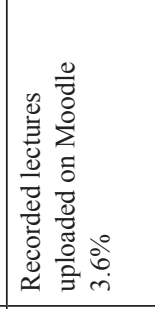 & $z \stackrel{\circ}{\circ}$ & z \\
\hline & 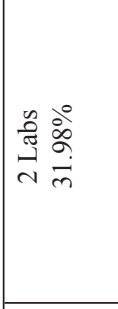 & 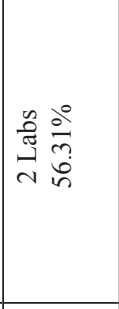 & 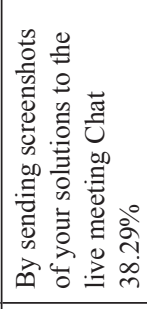 & 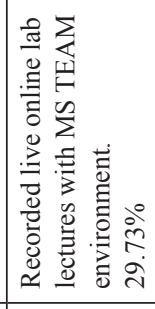 & $\varangle \underset{\substack{0 \\
\infty}}{\infty}$ & 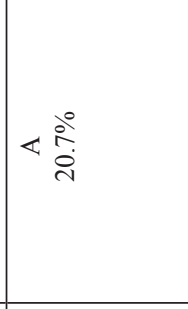 \\
\hline & 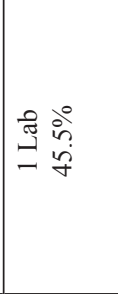 & 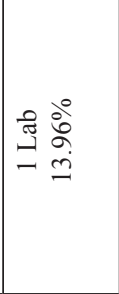 & 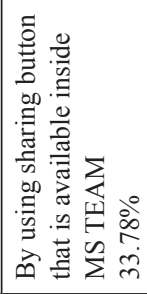 & 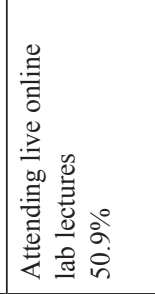 & $\llbracket \stackrel{\circ}{\stackrel{\circ}{a}}$ & 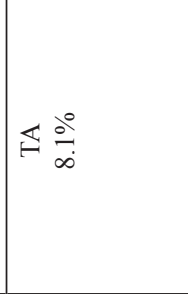 \\
\hline 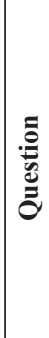 & 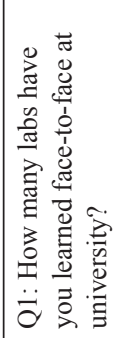 & 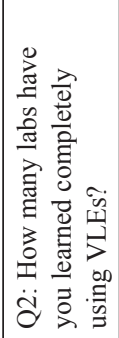 & 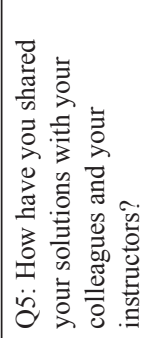 & 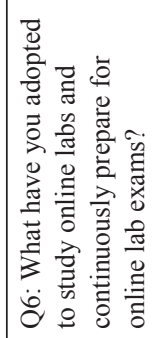 & 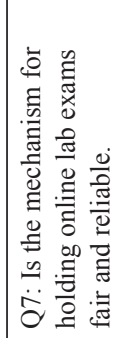 & 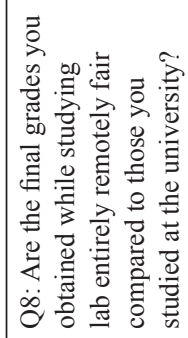 \\
\hline & 竞 & & 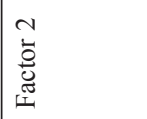 & & 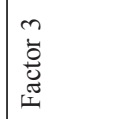 & \\
\hline
\end{tabular}




\begin{tabular}{|c|c|c|c|c|}
\hline & 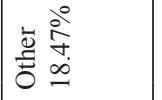 & \multirow{3}{*}{ 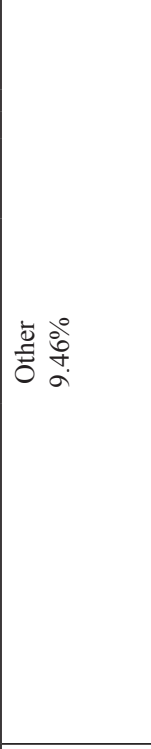 } & 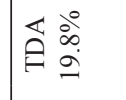 & 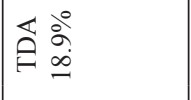 \\
\hline 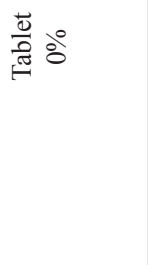 & 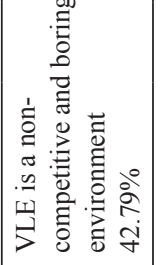 & & 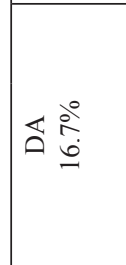 & 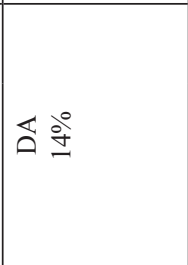 \\
\hline$\stackrel{\circ}{\stackrel{\circ}{\circ}} \stackrel{\circ}{\circ}$ & 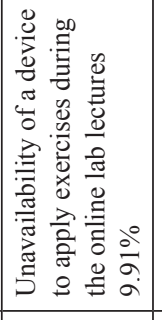 & & $z \stackrel{\text { خें }}{\text { خे }}$ & $z \stackrel{\partial}{\stackrel{\partial}{0}}$ \\
\hline 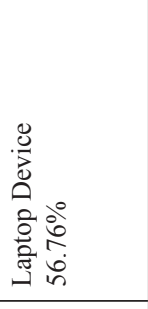 & 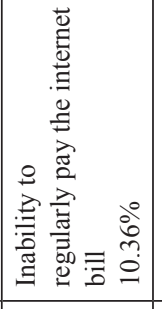 & 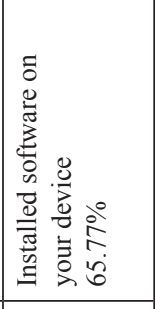 & $\varangle \frac{\circ}{\stackrel{0}{\circ}}$ & 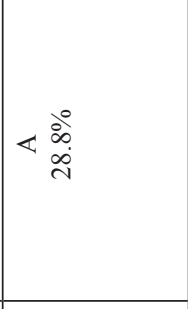 \\
\hline 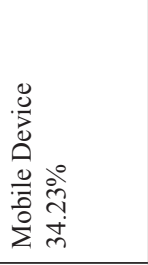 & 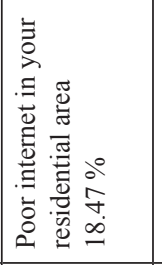 & 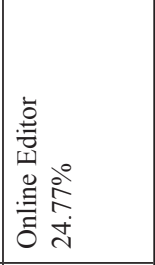 & $\varangle \stackrel{\stackrel{\circ}{े}}{\stackrel{\sim}{े}}$ & 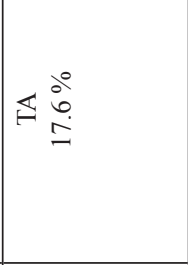 \\
\hline 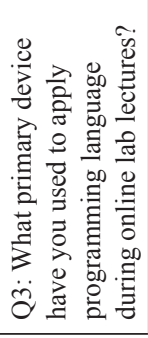 & 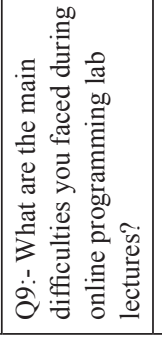 & 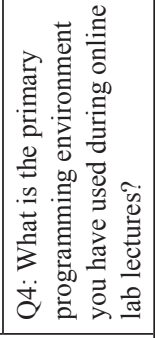 & 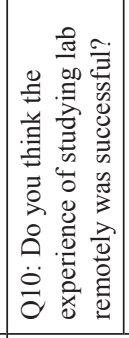 & 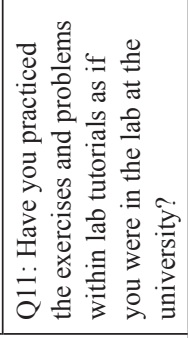 \\
\hline 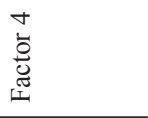 & & & 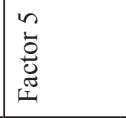 & \\
\hline
\end{tabular}




\subsection{Comparing student performance before and during the COVID-19 pandemic by analyzing the direct assessments via curves}

Direct assessments are the assessments of students that are derived from exams, quizzes, projects, and participation. This subsection compares the behavior of direct programming assessments for students before the COVID-19 pandemic and during the COVID-19 pandemic. The direct assessment is investigated using a final grade curve for all lab classes for a specific lab programming course. The research adopted the curves of object programming $2 \mathrm{Lab}(\mathrm{OOP} 2 \mathrm{Lab})$ as a case study for comparison purposes for scientific contribution. The OOP2 final grade curve for the first semester of the academic year (2019/2020) has been selected to study its significance for the period before the COVID-19 pandemic. The number of students who registered that semester was 133 , and 11 dropped the course. The OOP2 final grade curve for the second semester of the academic year 2020/2021 has been selected (the nearest curve in terms of the number of students has been selected to reduce the error rate) to study its influence during the COVID-19 pandemic. The number of students registered in that semester was 106 .

Figure 3 illustrates the curve of the final grades for the OOP2 Lab before the COVID19 pandemic and the curve of the final grades for the OOP2 Lab during the COVID-19 pandemic.

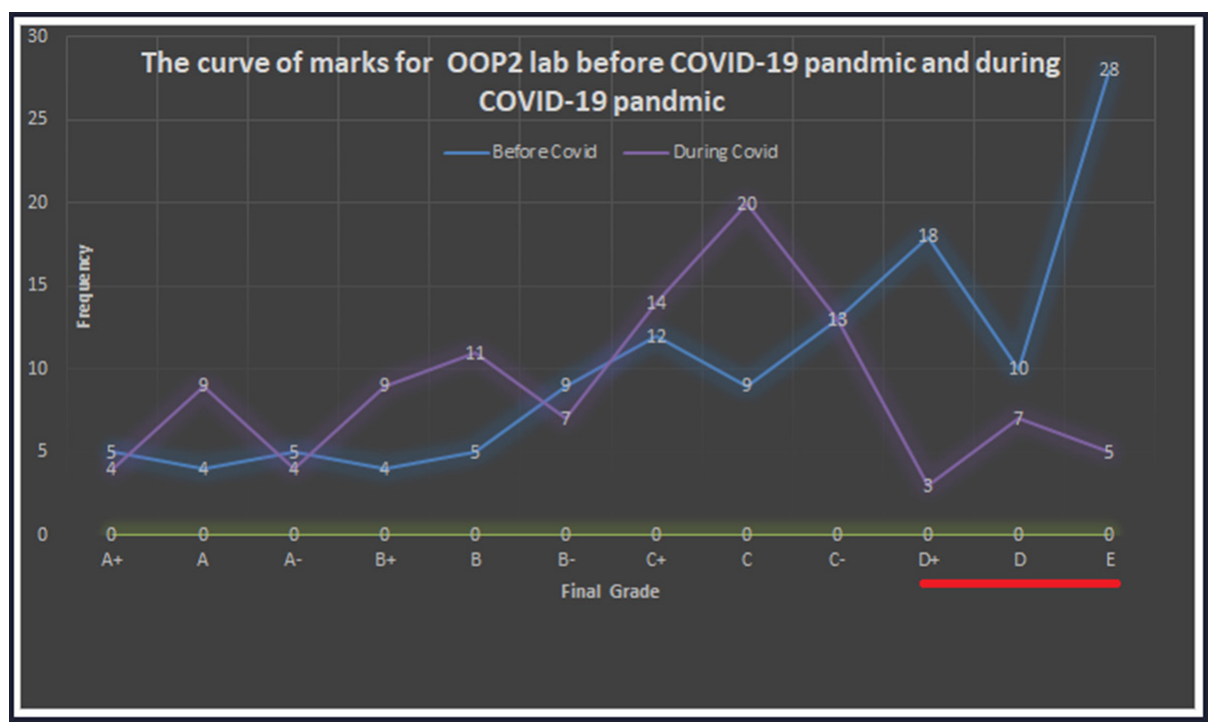

Fig. 3. The curve of the final grades for the OOP2 lab before the COVID-19 pandemic and the curve of the final grades for the OOP2 lab during the COVID-19 pandemic 
The last portion of the compared curves (from grades D+ to E) is mostly consistent with the rest of all the compared curves for other labs. The number of students that failed dramatically dropped. The justification for this phenomenon is that during the COVID-19 pandemic, many assessments for programming labs were granted based on the programming during online live lectures. Lab instructors have encouraged students to attend and participate during online lab lectures. Raising the students' morale is paramount, especially given that many students have felt the ramifications of the pandemic firsthand within their families, having lost family members due to infection.

\subsection{Comparing the performance of students before and during the COVID 19 pandemic by analyzing the direct assessments via independent t-test}

Using an independent t-test, the marks of students who studied Object-Oriented Programming Lab 2 before and during COVID-19 were analyzed. The data were collected from the first semester of academic years (2019/2020) for students who studied Object-Oriented Programming in person (sample 1) and from the second semester of academic years (2020/2021) for students who studied the same course lab remotely (sample 2). The size of sample 1 was 122 , and the second sample size was 106 . The data that has been used in this subsection are the same as that which has been utilized within the previous subsection so that the observations that have been inferred from the study will be related and consistent. The two selected samples are considered unpaired (independent) because the students who studied the OOP2 Lab before COVID-19 are different from the students who studied OOP2 in the lab during COVID-19. Before applying the independent t-test on two samples, the examination of normal distribution exhibits that the OOP2 lab marks of students before COVID-19 followed a normal distribution, whereas the OOP2 lab marks of students during COVID-19 did not follow a normal distribution. Table 3 depicts the results of the normal distribution test on two samples.

The data from the second sample did not follow the normal distribution $($ Sig $=.021<.05)$, emphasizing the impact of the adopted teaching methodology during COVID-19 and the adopted assessment system during COVID-19 on a normal distribution curve of final marks. Based on previous results, the second sample data has been transformed to check the required normal distribution condition for the t-test using the IBM SPSS statistical editor. The first declared variable for the independent t-test is the groups of students; group 1 students who studied OOP2 Lab before COVID-19, denoted by 1, and group 2 students who studied OOP2 Lab during COVID-19, denoted by 2 .

The second variable declared for the independent t-test is the marks of students. The primary purpose of using an independent t-test is to compare the means of two groups. 
The hypotheses of the t-test are:

- $\mathbf{H}_{\mathbf{0}}$ : there is no difference between the means of the marks for the students who studied OOP2 Lab before COVID-19 and the means of the marks for students who studied OOP2 Lab during COVID-19, and

- $\mathbf{H}_{1}$ : there is a difference between the means of the marks of students who studied OOP2 Lab before COVID and those who studied OOP2 Lab during COVID-19.

The independent t-test, as illustrated in Table 4, shows that rejecting $\mathrm{H}_{0}$ whereas the sig of $\mathbf{H}_{\mathbf{0}}=\mathbf{. 0 2 6}$ and it is less than $<\mathbf{0 . 0 5}$ and accepting the $\mathbf{H}_{\mathbf{1}}$. The results indicate a variance between the means of the marks of students who studied OOP2 Lab before COVID-19 and those who studied OOP2 Lab during COVID-19 in favor of the higher mean. Students' marks during COVID-19 have statistical significance, as depicted in Table 4 and Table 5. Two reasons lead to obtaining higher means for marks during COVID-19; the first reason is calculating a portion of the mark for participation and interaction during the lectures is to encourage students to attend and engage using a new learning methodology. The second reason is the inability to fully control the cheating process during online exams.

Table 3. The results of the normal distribution test on two samples

\begin{tabular}{|l|l|l|l|l|l|c|c|}
\hline \multicolumn{10}{|c|}{ Tests of Normality } \\
\hline \multirow{2}{*}{} & \multicolumn{1}{|c|}{ Groups } & \multicolumn{2}{|c|}{ Kolmogorov-Smirnova } & \multicolumn{3}{c|}{ Shapiro-Wilk } \\
\cline { 3 - 9 } & & Statistic & df & Sig. & Statistic & df & Sig. \\
\hline $\begin{array}{l}\text { OOP2 } \\
\text { Lab } \\
\text { Final } \\
\text { Mark }\end{array}$ & $\begin{array}{l}\text { Students Study OOP2 } \\
\text { Lab Face to Face before } \\
\text { COVID-19 }\end{array}$ & .055 & 122 & $.200^{*}$ & .988 & 122 & .361 \\
\cline { 2 - 9 } & $\begin{array}{l}\text { Students Study OOP2 Lab } \\
\text { online during COVID-19 }\end{array}$ & .082 & 106 & .075 & .971 & 106 & .021 \\
\hline
\end{tabular}

Notes: *This is a lower bound of the true significance. aLilliefors Significance Correction. 


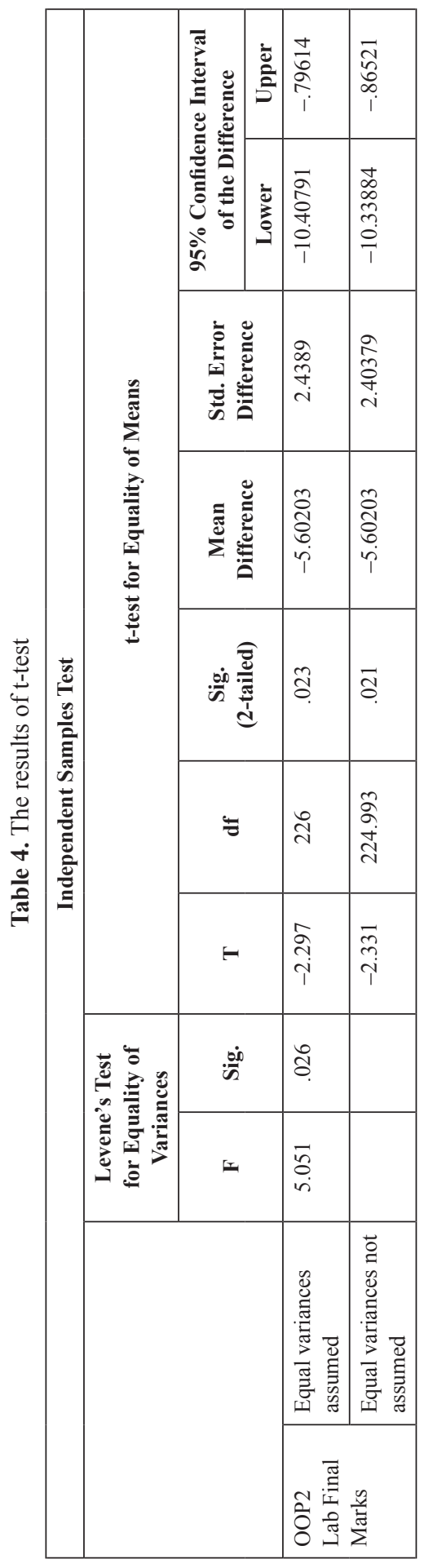

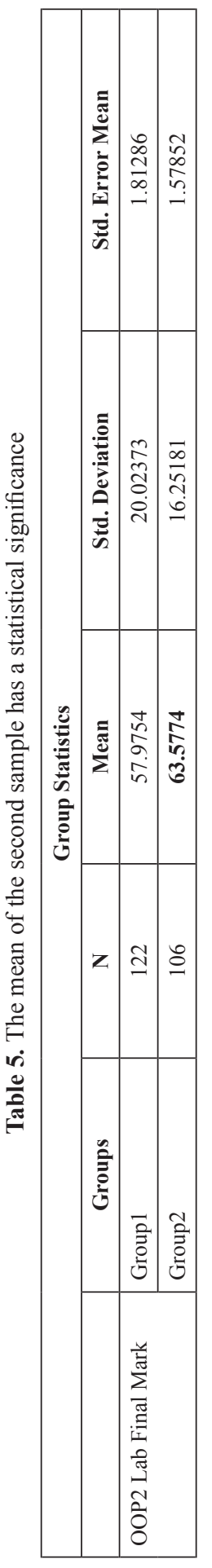

http://www.i-jim.org 


\section{$7 \quad$ Limitations of study}

The sudden shift in educational planning had caused severe chaos [9]. This emergent situation was difficult for teachers, students, and families [29] [10]. Teachers and students experienced increased stress and anxiety as a result of the transition to fully online teaching and learning [1]. Moreover, many students and faculty members were significantly affected by the work-family conflict and life satisfaction level during the COVID-19 Pandemic [11]. Several factors affected the online learning process during COVID-19. Almaiah et al. [16] investigated the factors that influenced the eLearning process. The lack of internet connectivity and information technology infrastructure, broadband connectivity problems in rural areas, and a shortage of laptops and PCs had significantly affected the learning process. The financial issue during COVID-19 was a crucial factor for students and a reason to utilize smartphones for online learning [16] [14]. Obeidat et al. study showed that most students (79.7\%) at Hashemite University had accessed educational material using smartphones rather than PCs or tablets [15].

Furthermore, due to insufficient educational materials and limited technical skills, distance learning was a complex process [17] [8]. Martín et al. [18] study's results from the Faculty of Education Sciences at the University of Granada showed dissatisfaction with students' perspectives toward distance learning during COVID-19. Students with physical difficulties, especially hearing impairments, had additional challenges than average students did. Findings of a Krishnan et al. study [19] showed that deaf and hard-of-hearing students faced problems with their hearing devices, which disrupted their comprehension of the lesson, and they were emotionally affected during online classes due to a lack of help with online devices. The following section will focus on practical labs' importance in university education.

Inexperience in dealing with pandemics delayed finding the final unified framework of online teaching programming languages labs during the lockdown. At the beginning of the pandemic (second semester of the academic year 2019/2020), each instructor adopted methodology and tools to teach lab remotely till the university systemized the general layouts of teaching during COVID-19. The study required two academic semesters (first semester 2020/2021 and second semester 2020/2021) to be conducted and its results to be reliable. Each student has to study at least two labs online to build a dependable perception toward teaching programming labs remotely.

\section{Conclusions and future works}

This research proposes a new teaching methodology for teaching labs online. The proposed methodology had been applied for a year during the COVID-19 lockdown. The adopted approach for teaching IT labs had been assembled to provide live virtual lab classes. Lab instructors provided students with online editors and software simulators to enable students who did not have a PC to apply the exercises. Live lectures were recorded and uploaded directly to the Microsoft team channel. Furthermore, social media applications were utilized as extra resources. A validated web survey using Pearson Coefficients Correlations, an independent t-test applied to students' marks, and 
studying the behavior of the grades curves were the study methodology that has been exploited to obtain the study's goals. Three goals were addressed in the introduction. Objective 1 has been achieved through analyzing the study survey, which revealed that $42.79 \%$ of students consider that VLE is the main difficulty encountered during COVID-19, as they believe VLE creates a tiresome and uncompetitive environment. The study survey also discovered that $34.23 \%$ of students used mobile phones as the primary device to code during COVID-19. The university must find strategies to distribute laptops to less fortunate students. The second objective of the study has been attained via a study survey. $47.3 \%$ of students have a positive attitude toward learning programming labs online. The third objective is accomplished by comparing the marks of students of OOP2 Lab before and during COVID-19 via applying an independent t-test and by analyzing the behavior of grades' curves before and during COVID-19, the results of the independent t-test reveal that the marks of students during COVID-19 have statistical significance. The behavior of the grades' curve changed, with a considerable decrease in the number of failed students. The proposed methodology for teaching online programming labs showed a successful approach to creating a training environment similar to classes on campus, but, at the same time, it must be improved to create a more competitive atmosphere in the future. This study represents the cornerstone for many future studies that will be helpful to ensure the continuity of teaching programming languages labs during natural disasters such as earthquakes, floods, and hurricanes. Gamification can be attached to our suggested approach to creating an atmosphere of enthusiasm during programming. The assessment system and remote fraud prevention techniques must be revised, investigated, and scrutinized within dedicated research to present an integrated assessment component embedded within our proposed teaching programming languages approach.

\section{References}

[1] UNESCO (2020). COVID-19 Impact on Education Data. COVID-19 Education Disruption and Response. The United Nations Educational, Scientific and Cultural Organization, UNESCO. Paris, France.

[2] Pinto, M., and Leite, C. Digital technologies in support of students learning in higher education: A literature review. Digit. Educ. 2020, 37, 1-18. https://doi.org/10.1344/ der.2020.37.343-360

[3] Obeidallah, R., and Shdaifat, A. (2020). "An Evaluation and Examination of Quiz Tool within Open-Source Learning Management Systems." International Journal of Emerging Technologies in Learning. 15(10), 191-201. https://doi.org/10.3991/ijet.v15i10.11638

[4] Shdiafat, A., and Obeidallah, R. (2019). Quiz Tool Within Moodle and Blackboard Mobile Applications. International Journal of Interactive Mobile Technologies. 13(8), 32-42. https://doi.org/10.3991/ijim.v13i08.10552

[5] Obeidallah, R., Ghazal, G. and Shdaifat, A. (2016). 'The experience of using Moodle and Elluminate Live! as learning tools in the Hashemite University case study: computer skills course.' International Journal of Business Information Systems. 23(1), 44-53. https://doi. org/10.1504/IJBIS.2016.078022

[6] Lurvnik: UNESCO. (2020, March 30). COVID-19 Webinar: A new world for teachers, education's frontline workers. Marrënga https://en.unesco.org/news/covid-19-webinar-newworldteachers-educations-frontline-workers 
[7] Cardoso, M., Barroso, R., Castro, A. V., and Rocha, Á. (2017). Virtual Programming Labs in the Computer Programming Learning Process, Preparing a Case Study. EDULEARN17 Proceedings, 7146-7155. https://doi.org/10.21125/edulearn.2017.2704

[8] Tadesse, S., and Muluye, W. (2020). The Impact of COVID-19 Pandemic on Education System in Developing Countries: A Review. Open Journal of Social Sciences. 8, 159-170. https://doi.org/10.4236/jss.2020.810011

[9] Thomas, C. J. (2020). Coronavirus and Challenging Times for Education in Developing Countries April 13. Brookings. Retrieved from https://www.brookings. edu/blog/education-plus-development/2020/04/13/coronavirus-and-challengingtimes-for-education-in-developing-countries/

[10] Hodges, C., Moore, S., Lockee, B.,Trust, T., and Bond, A. The Difference Between Emergency Remote Teaching and Online Learning. Educ. Rev. (2020). Accessed on July 24, 2020, at: https://er.educause.edu/articles/2020/3/the-difference-between-emergencyremote-teaching-andonline-learning

[11] Karakose, T., Yirci, R., and Papadakis, S. (2021). Exploring the Interrelationship between COVID-19 Phobia, Work-Family Conflict, Family-Work Conflict, and Life Satisfaction among School Administrators for Advancing Sustainable Management. Sustainability. 13(15), 8654. https://doi.org/10.3390/su13158654

[12] Yokozeki: UNESCO. (2020, March 30). COVID-19 Webinar: A New World for Teachers, Education's Frontline Workers. Marrënga. https://en.unesco.org/news/covid-19-webinarnewworld-teachers-educations-frontline-workers

[13] Mishra, L., Gupta, T., and Shree, A. (2020). Online Teaching-Learning in Higher Education during Lockdown Period of COVID-19 Pandemic. International Journal of Educational Research Open. 1. 100012. https://doi.org/10.1016/j.ijedro.2020.100012

[14] Muthuprasad, T., Aiswarya, S., Aditya, K. S., and Grish, K. J. (2021). Students' Perception and Preference for Online Education in India During COVID-19 Pandemic. Social Sciences \& Humanities Open. Vol. 3, No. 1, 100101, ISSN 2590-2911. https://doi.org/10.1016/ j.ssaho.2020.100101

[15] Obeidat, A., Rana O., and Mohamad, A. (2020). The Effectiveness of Adopting e-Learning during COVID-19 at Hashemite University. (IJACSA) International Journal of Advanced Computer Science and Applications. Vol. 11, No. 12. https://doi.org/10.14569/ IJACSA.2020.0111212

[16] Amin Almaiah, M., Al-Khasawneh, A. and Al Thunibat, A. (2020). Exploring the Critical Challenges and Factors Influencing the e-Learning System usage During the COVID-19 Pandemic. Education and Information Technologies. 22: 1-20. https://doi.org/10.1007/ s10639-020-10219-y

[17] Mustafa, N. (2020). Impact of the 2019-20 Coronavirus Pandemic on Education. International Journal of Health Preferences Research. 1-12.

[18] Torres Martín, C., Acal, C., El Honrani, M., and Mingorance Estrada, Á.C. (2021). Impact on the Virtual Learning Environment Due to COVID-19. Sustainability. 13, 582. https://doi. org/10.3390/su13020582

[19] Krishnan, Isai A. et al. (2020). "Challenges Faced by Hearing Impairment Students During COVID-19." Malaysian Journal of Social Sciences and Humanities. 5(8). https://doi. org/10.47405/mjssh.v5i8.472

[20] Rai, S. (2020, August). Improving computer science lab feedback methods. In 2020 IEEE Integrated STEM Education Conference (ISEC), 1-4. IEEE. https://doi.org/10.1109/ ISEC49744.2020.9280738

[21] Khan, I. A., Iftikhar, M., Hussain, S. S., Rehman, A., Gul, N., Jadoon, W., and Nazir, B. (2020). Redesign and validation of a computer programming course using Inductive Teaching Method. PloS one, 15(6), e0233716. https://doi.org/10.1371/journal.pone.0233716 
[22] BayisaNateaSima, Sasikuma Perumal. IOSR Journal of Computer Engineering (IOSR-JCE) e-ISSN: 2278-0661, p-ISSN: 2278-8727, Vol. 21, No. 6, Ser. I (Nov-Dec 2019), 08-15.

[23] Thuné, M., and Eckerdal, A. (2019). Analysis of Students' Learning of Computer Programming in a Computer Laboratory Context. European Journal of Engineering Education. 44(5), 769-786. https://doi.org/10.1080/03043797.2018.1544609

[24] Alves, P., Miranda, L., and Morais, C. (2017). The Influence of Virtual Learning Environments in Students' Performance. Universal Journal of Educational Research. 5(3), 517-527, 2017. https://doi.org/10.13189/ujer.2017.050325

[25] Aris, H. (2015, July). Improving Students' Performance in Introductory Programming Subject: a Case Study. In 2015 10th International Conference on Computer Science \& Education (ICCSE), 657-662, IEEE. https://doi.org/10.1109/ICCSE.2015.7250328

[26] Papadakis, S., and Kalogiannakis, M. (2019). Evaluating the Effectiveness of a Game-based Learning Approach in Modifying Students' Behavioural Outcomes and Competence, in an Introductory Programming Course. A case study in Greece. International Journal of Teaching and Case Studies. 10(3), 235-250. https://doi.org/10.1504/IJTCS.2019.10024369

[27] Al Ahmad, Ayat and Randa Obeidallah. (2019). "The Impact of Social Networks on Students' Academic Achievement in Practical Programming Labs." International Journal of Advanced Computer Science and Applications (IJACSA), 10(11). https://doi.org/10.14569/ IJACSA.2019.0101108

[28] Papadakis, S. (2021). Advances in Mobile Learning Educational Research (AMLER): Mobile learning as an educational reform. Advances in Mobile Learning Educational Research. 1(1), 1-4. https://doi.org/10.25082/AMLER.2021.01.001

[29] Sahoo, B. P., Gulati, A., and Haq, I. U. (2021). Covid 19 and Challenges in Higher Education: An Empirical Analysis. International Journal of Emerging Technologies in Learning, 16(15). https://doi.org/10.3991/ijet.v16i15.23005

[30] Pebriantika, L., Wibawa, B., and Paristiowati, M. (2021). Adoption of Mobile Learning: The Influence and Opportunities for Learning During the Covid-19 Pandemic. International Journal of Interactive Mobile Technologies, 15(5). https://doi.org/10.3991/ijim.v15i05.21067

[31] Novaliendry, D., Huda, A., Cuhanazriansyah, M. R., Sani, H. K., Hendra, H., and Karnando, J. (2021). E-Learning Based Web Programming Course in the COVID 19 Pandemic Time. International Journal of Interactive Mobile Technologies, 16(20). https://doi. org/10.3991/ijim.v15i20.23749

\section{Authors}

Ayat Al Ahmad works as a lecturer at Faculty of Prince Al-Hussein Bin Abdallah II for IT, Department of Computer Science and Applications, The Hashemite University, P. O box 330127, Zarqa 13133, Jordan, Email: Ayat@hu.edu.jo

Randa Obeidallah works as an instructor in Faculty of Prince Al-Hussein Bin Abdallah II for IT, Department of Computer Information Systems, The Hashemite University, P. O box 330127, Zarqa 13133, Jordan, Email: randa.ali@hu.edu.jo

Article submitted 2021-09-26. Resubmitted 2021-12-03. Final acceptance 2021-12-25. Final version published as submitted by the authors. 